\title{
Oral-facial-digital syndrome type VI: is C5orf42 really the major gene?
}

\author{
Marta Romani · Francesca Mancini • Alessia Micalizzi • Andrea Poretti • Elide Miccinilli • Patrizia Accorsi \\ Emanuela Avola • Enrico Bertini · Renato Borgatti · Romina Romaniello · Serdar Ceylaner · Giangennaro Coppola • \\ Stefano D'Arrigo • Lucio Giordano • Andreas R. Janecke • Mario Lituania • Kathrin Ludwig • Loreto Martorell • \\ Tommaso Mazza $\cdot$ Sylvie Odent $\cdot$ Lorenzo Pinelli $\cdot$ Pilar Poo $\cdot$ Margherita Santucci $\cdot$ Sabrina Signorini $\cdot$ \\ Alessandro Simonati · Ronen Spiegel · Franco Stanzial • Maja Steinlin · Brahim Tabarki • Nicole I. Wolf · \\ Federica Zibordi · Eugen Boltshauser · Enza Maria Valente
}

Received: 30 July 2014 / Accepted: 1 November 2014 / Published online: 19 November 2014

(C) The Author(s) 2014. This article is published with open access at Springerlink.com

\begin{abstract}
Oral-facial-digital type VI syndrome (OFDVI) is a rare phenotype of Joubert syndrome (JS). Recently, C5orf42 was suggested as the major OFDVI gene, being mutated in 9 of 11 families ( $82 \%$ ). We sequenced C5orf 42 in $313 \mathrm{JS}$ probands and identified mutations in $28(8.9 \%)$, most with a phenotype of pure JS. Only 2 out of 17 OFDVI patients $(11.7 \%)$ were mutated. A comparison of mutated vs. non-mutated OFDVI patients showed that preaxial and mesoaxial polydactyly, hypothalamic hamartoma and other congenital defects may predict C5orf42 mutations, while tongue hamartomas are more common in negative patients.
\end{abstract}

Electronic supplementary material The online version of this article (doi:10.1007/s00439-014-1508-3) contains supplementary material, which is available to authorized users.

M. Romani - F. Mancini · A. Micalizzi - E. Miccinilli · T. Mazza · E. M. Valente $(\bowtie)$

Lab. Mendel, IRCCS Casa Sollievo della Sofferenza, Viale

Regina Margherita 261, 00198 Rome, Italy

e-mail: e.valente@css-mendel.it

M. Romani

e-mail:m.romani@css-mendel.it

A. Micalizzi

Department of Biological and Environmental Science,

University of Messina, Messina, Italy

\section{A. Poretti}

Section of Pediatric Neuroradiology, Division of Pediatric

Radiology, The Johns Hopkins School of Medicine,

Baltimore, MD, USA

\section{P. Accorsi · L. Giordano}

Pediatric Neuropsychiatric Division, Spedali Civili,

Brescia, Italy

E. Avola

Unit of Pediatrics and Medical Genetics, I.R.C.C.S. Associazione

Oasi Maria Santissima, Troina, Italy
Oral-facial-digital type VI syndrome (OFDVI) is a rare phenotype in the spectrum of Joubert syndrome (JS) and is defined by the presence of the "molar tooth sign" (MTS) with at least one of these findings: (1) tongue hamartoma and/or additional lingual frenula and/or upper lip notch; (2) mesoaxial polydactyly; (3) hypothalamic hamartoma. Other oral-facial (e.g. cleft lip and palate) or digital (e.g. postaxial and preaxial polydactyly) abnormalities can also be present (Poretti et al. 2012).

Mutations in TMEM216 and in OFD1 have been reported in few OFDVI patients (Coene et al. 2009; Darmency-Stamboul et al. 2013; Valente et al. 2010). A recent study identified mutations in the C5orf 42 gene in nine of 11 OFDVI (82\%) families (including four living children

\footnotetext{
E. Bertini

Unit of Neuromuscular and Neurodegenerative Disorders, Laboratory of Molecular Medicine, Bambino Gesù Children's Research Hospital, Rome, Italy

R. Borgatti $\cdot$ R. Romaniello

Neuropsychiatry and Neurorehabilitation Unit, Scientific Institute, IRCCS Eugenio Medea, Bosisio Parini, Lecco, Italy

S. Ceylaner

Intergen Genetic Diagnosis, Research and Education Center, Ankara, Turkey

G. Coppola $\cdot$ E. M. Valente

Section of Neuroscience, Department of Medicine and Surgery, University of Salerno, Salerno, Italy
}

S. D'Arrigo

Developmental Neurology Division, Fondazione IRCCS Istituto Neurologico C. Besta, Milan, Italy

A. R. Janecke

Department of Pediatrics I and Division of Human Genetics, Innsbruck Medical University, Innsbruck, Austria 


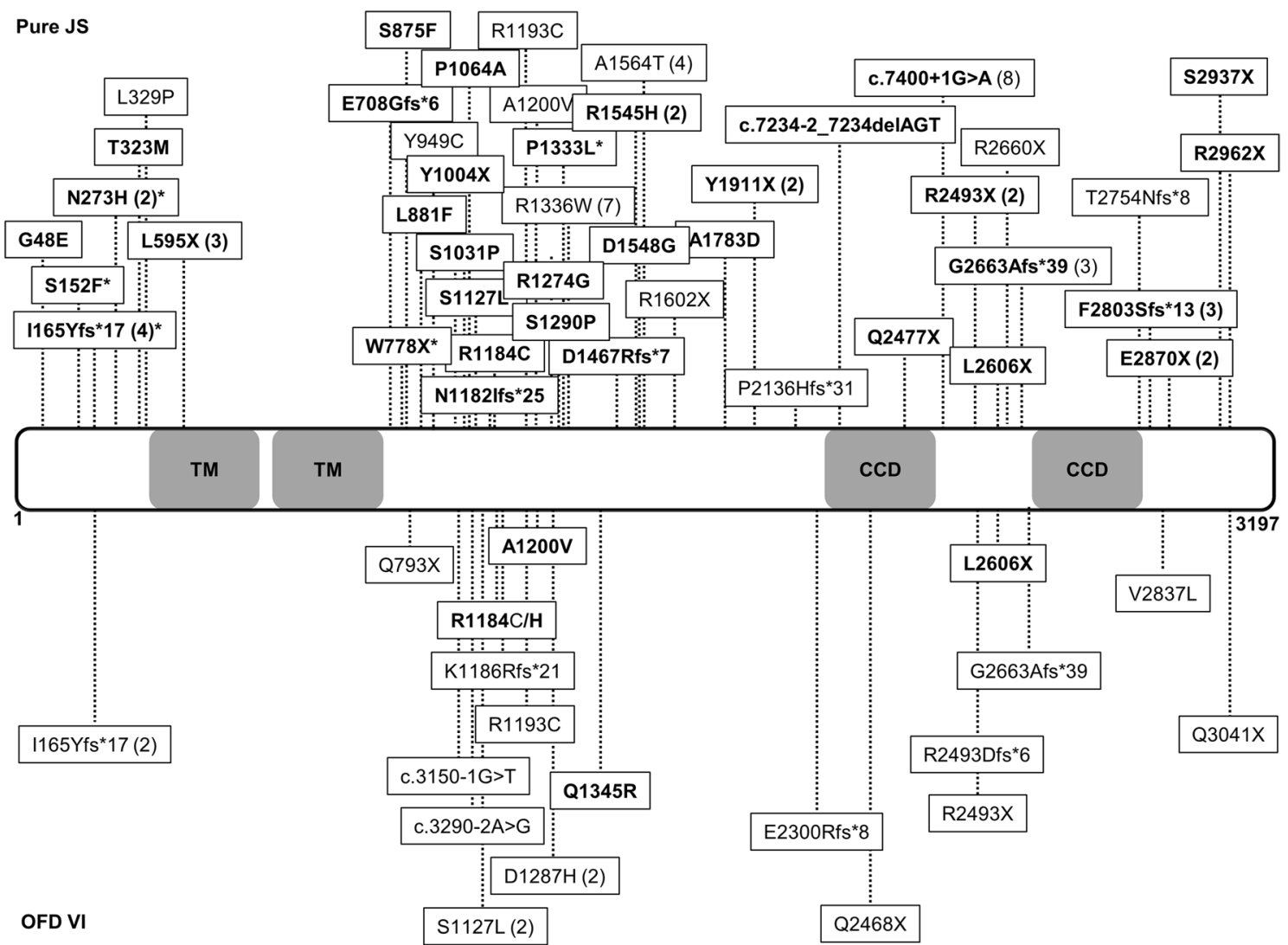

Fig. 1 Schematic representation of C5orf42 protein structure and distribution of all reported mutations. The two predicted transmembrane domains (TM, amino acids 592-612 and 631-651) and the two predicted coiled coil domains (CCD, amino acids 2,457-2,487 and 2,691-2,724) are shown. Mutations found in patients with pure Jou-

\section{Lituania}

Preconceptional and Prenatal Physiopathology,

Galliera Hospital, Genoa, Italy

\section{K. Ludwig}

Surgical Pathology and Cytopathology Unit, Department of Medicine (DIMED), University of Padova, Padua, Italy

\section{Martorell}

Department of Molecular Genetics, Hospital

Sant Joan de Déu, Barcelona, Spain

\section{S. Odent}

Service de Génétique Médicale, CHU Hôpital Sud,

Rennes, France

\section{Pinelli}

Department of Neuroradiology, Spedali Civili, Brescia, Italy

\section{P. Poo}

Department of Neurology, Hospital Sant Joan de Déu,

Barcelona, Spain

\section{Santucci}

Pediatric Neuropsychiatry Unit, IRCCS Istituto di Scienze

Neurologiche, Bologna, Italy bert syndrome and with OFDVI are presented in the upper and lower parts of the figure, respectively. Mutations identified in the present study are in bold. In brackets are the numbers of patients in whom each mutation has been identified. Asterisk indicates clinical data not available

S. Signorini

Unit of Child Neurology and Psychiatry, Centre of Child Neuro-ophthalmology, C. Mondino National Neurological Institute, Pavia, Italy

A. Simonati

Department of Neurological Sciences and Movement-Neurology (Child Neurology), University of Verona, Verona, Italy

\section{R. Spiegel}

Emek Medical Center, Genetic Institute, Afula, Israel

F. Stanzial

Department of Pediatrics, Genetic Counselling Service, Regional Hospital of Bolzano, Bolzano, Italy

\section{Steinlin}

Department of Pediatric Neurology, University Children's Hospital, Bern, Switzerland

B. Tabarki

Division of Pediatric Neurology, Prince Sultan Military Medical City, Riyadh, Saudi Arabia 
Table 1 Comparison of clinical features in C5orf42 mutated vs. non-mutated OFDVI patients

\begin{tabular}{|c|c|c|c|}
\hline & Mutated & Non-mutated & $p$ \\
\hline Any oral-facial feature & $7 / 12(58 \%)$ & $17 / 17(100 \%)$ & 0.006 \\
\hline Tongue hamartomas/multiple lingual frenula ${ }^{a}$ & $6 / 12(50 \%)$ & $17 / 17(100 \%)$ & 0.002 \\
\hline Other oral-facial features ${ }^{b}$ & $4 / 12(33 \%)$ & $5 / 17(29 \%)$ & n.s. \\
\hline Any polydactyly & $14 / 14(100 \%)$ & $13 / 17(76 \%)$ & n.s. \\
\hline Mesoaxial polydactyly ${ }^{\mathrm{a}}$ & $7 / 14(50 \%)$ & $1 / 17(6 \%)$ & 0.01 \\
\hline Preaxial polydactyly & $14 / 14(100 \%)$ & $5 / 17(29 \%)$ & 0.0001 \\
\hline Postaxial polydactyly & $9 / 14(64 \%)$ & $10 / 17(59 \%)$ & n.s. \\
\hline Any CNS abnormality besides MTS & $8 / 14(57 \%)$ & $4 / 17(24 \%)$ & n.s. \\
\hline Hypothalamic hamartoma $^{\mathrm{a}}$ & $6 / 14(43 \%)$ & $1 / 17(6 \%)$ & 0.03 \\
\hline Occipital encephalocele & $2 / 14(14 \%)$ & $1 / 17(6 \%)$ & n.s. \\
\hline Other CNS abnormalities ${ }^{c}$ & $4 / 14(29 \%)$ & $2 / 17(12 \%)$ & n.s. \\
\hline Retinal/renal/hepatic involvement & $0 / 14$ & $4 / 17(24 \%)$ & n.s. \\
\hline Retinopathy (only living patients) & $0 / 2$ & 3 e/17 (18\%) & n.s. \\
\hline Nephronophthisis (only living patients) & $0 / 2$ & $2 \mathrm{e} / 17(12 \%)$ & n.s. \\
\hline Cystic dysplastic kidneys & $0 / 14$ & $0 / 17$ & n.s. \\
\hline Congenital liver fibrosis & $0 / 14$ & $0 / 17$ & n.s. \\
\hline Other congenital abnormalities outside the $\mathrm{CNS}^{\mathrm{d}}$ & $8 / 14(57 \%)$ & $1 / 17(6 \%)$ & 0.004 \\
\hline
\end{tabular}

C5orf42 mutated patients include the 12 patients from 9 families reported by Lopez et al. (2014) and the two patients from the present paper; C5orf42 non-mutated patients $(n=17)$ are all from the present cohort, and include one patient mutated in OFD1 (see text) and 16 patients from 14 families. Statistical comparisons were made by Fisher's exact test

a Sufficient for diagnosis of OFDVI in association with the MTS

b Cleft lip and/or palate, tooth abnormalities, lobulated tongue, short frenula

${ }^{c}$ Porencephaly, nodular heterotopia, polymicrogyria, corpus callosum abnormalities, hydrocephalus, arhinencephaly

${ }^{\mathrm{d}}$ Abnormal ribs or long bones, cubitus valgus, heart or aortic defects, uterus septation, common mesentery, coloboma, microphthalmia, Hirschsprung disease, scoliosis

e Includes two siblings

and eight fetuses), suggesting that C5orf42 could represent the major causative gene for OFDVI (Lopez et al. 2014).

As part of a ciliopathy research project, we sequenced C5orf42 in 313 JS probands, and identified pathogenic mutations in $28(8.9 \%)$ (Fig. 1). Only two out of 17 OFDVI probands in our cohort $(11.7 \%)$ carried C5orf 42 mutations, while one was mutated in $O F D 1$. No mutations were detected in the remaining 14 (82.3\%) OFDVI patients

\author{
N. I. Wolf \\ Department of Child Neurology, VU University Medical Center \\ and Neuroscience Campus Amsterdam, Amsterdam, \\ The Netherlands \\ F. Zibordi \\ Department of Child Neurology, Fondazione IRCCS Istituto \\ Neurologico "Carlo Besta", Milan, Italy \\ E. Boltshauser \\ Department of Pediatric Neurology, University Children's \\ Hospital, Zurich, Switzerland \\ E. M. Valente \\ Neurogenetics Unit, CSS-Mendel Institute, Viale Regina \\ Margherita 261, 00198 Rome, Italy
}

in all tested genes (see Supplementary material online for methods, characterization of mutations and clinical features of mutated OFDVI patients).

To explain the striking discrepancy between our findings and those reported by Lopez et al., we compared clinical features in C5orf42 mutated $(n=14)$ vs. non-mutated $(n=17)$ OFDVI patients (Table 1). Preaxial and mesoaxial polydactyly, hypothalamic hamartomas and other congenital abnormalities were significantly more frequent in the mutated group, while tongue hamartomas or multiple lingual frenula occurred more commonly in non-mutated patients. Other oral-facial features, postaxial polydactyly and other brain abnormalities were equally represented in both groups. Despite the limited number of patients, these findings suggest that the current diagnostic criteria for OFDVI include two main phenotypic groups, one with preaxial and/or mesoaxial polydactyly and frequent additional congenital anomalies (for which C5orf42 is the major causative gene), and another with less severe presentation and prevalent oral-facial involvement, which genetic causes still remain to be identified.

Twenty-seven C5orf42 mutated patients (from 23 families) in our study had pure JS (with retinopathy in one), 
while clinical data were unavailable in three. Considering all reported $C 5$ orf42 mutated patients $(n=58)$, over twothirds showed a pure JS phenotype while only $24 \%$ has OFDVI (Supplementary Table 1). Kidney or liver involvement was never noted, while polydactyly (mainly preaxial) was present in nearly half of mutated patients regardless of the phenotype. These findings delineate a specific C5orf42related phenotype, and suggest a major role for this gene in limb development.

Overall, the identification of mutations in 28 of $313 \mathrm{JS}$ probands makes $C 5$ orf42 a major contributor to the pathogenesis of this ciliopathy. How mutations in the same gene may cause pure JS or a much more severe oral-facial-digital syndrome remains an open question. Genotype-phenotype correlations seem to fail, since truncating and missense mutations affecting the entire length of the protein are detected in patients with either pure or OFDVI presentations (Fig. 1). As suggested for other ciliopathies, it is conceivable that additional, yet unidentified variants in distinct genes may act as genetic modifiers able to influence the penetrance and expression of oral-facial and digital features in patients bearing C5orf42 mutations.

Acknowledgments This work was partly supported by grants from the European Research Council (ERC Starting Grant 260888), the Telethon Foundation Italy (Grant GGP13146), and the Italian Ministry of Health (Ricerca Corrente 2014, Ricerca Finalizzata Malattie Rare 2008).

Open Access This article is distributed under the terms of the Creative Commons Attribution License which permits any use, distribution, and reproduction in any medium, provided the original author(s) and the source are credited.

\section{References}

Coene KL, Roepman R, Doherty D, Afroze B, Kroes HY, Letteboer SJ, Ngu LH, Budny B, van Wijk E, Gorden NT, Azhimi M, Thauvin-Robinet C, Veltman JA, Boink M, Kleefstra T,
Cremers FP, van Bokhoven H, de Brouwer AP (2009) OFD1 is mutated in $\mathrm{X}$-linked Joubert syndrome and interacts with LCA5-encoded lebercilin. Am J Hum Genet 85:465-481. doi:10.1016/j.ajhg.2009.09.002

Darmency-Stamboul V, Burglen L, Lopez E, Mejean N, Dean J, Franco B, Rodriguez D, Lacombe D, Desguerres I, CormierDaire V, Doray B, Pasquier L, Gonzales M, Pastore M, Crenshaw ML, Huet F, Gigot N, Aral B, Callier P, Faivre L, Attie-Bitach T, Thauvin-Robinet C (2013) Detailed clinical, genetic and neuroimaging characterization of OFD VI syndrome. Eur J Med Genet 56:301-308. doi:10.1016/j.ejmg.2013.03.004

Lopez E, Thauvin-Robinet C, Reversade B, Khartoufi NE, Devisme L, Holder M, Ansart-Franquet H, Avila M, Lacombe D, Kleinfinger P, Kaori I, Takanashi JI, Le Merrer M, Martinovic J, Noel C, Shboul M, Ho L, Guven Y, Razavi F, Burglen L, Gigot N, Darmency-Stamboul V, Thevenon J, Aral B, Kayserili H, Huet F, Lyonnet S, Le Caignec C, Franco B, Riviere JB, Faivre L, Attie-Bitach T (2014) C5orf42 is the major gene responsible for OFD syndrome type VI. Hum Genet 133:367-377. doi:10.1007/ s00439-013-1385-1

Poretti A, Vitiello G, Hennekam RC, Arrigoni F, Bertini E, Borgatti R, Brancati F, D’Arrigo S, Faravelli F, Giordano L, Huisman TA, Iannicelli M, Kluger G, Kyllerman M, Landgren M, Lees MM, Pinelli L, Romaniello R, Scheer I, Schwarz CE, Spiegel R, Tibussek D, Valente EM, Boltshauser E (2012) Delineation and diagnostic criteria of Oral-Facial-Digital Syndrome type VI. Orphanet J Rare Dis 7:4. doi:10.1186/1750-1172-7-4

Valente EM, Logan CV, Mougou-Zerelli S, Lee JH, Silhavy JL, Brancati F, Iannicelli M, Travaglini L, Romani S, Illi B, Adams M, Szymanska K, Mazzotta A, Lee JE, Tolentino JC, Swistun D, Salpietro CD, Fede C, Gabriel S, Russ C, Cibulskis K, Sougnez C, Hildebrandt F, Otto EA, Held S, Diplas BH, Davis EE, Mikula M, Strom CM, Ben-Zeev B, Lev D, Sagie TL, Michelson M, Yaron Y, Krause A, Boltshauser E, Elkhartoufi N, Roume J, Shalev S, Munnich A, Saunier S, Inglehearn C, Saad A, Alkindy A, Thomas S, Vekemans M, Dallapiccola B, Katsanis N, Johnson CA, Attie-Bitach T, Gleeson JG (2010) Mutations in TMEM216 perturb ciliogenesis and cause Joubert, Meckel and related syndromes. Nat Genet 42:619-625. doi:10.1038/ng.594 